\title{
PHOTODISSOCIATION AND SPECTROSCOPY OF \\ GAS PHASE BIMETALLIC CLUSTERS
}

\author{
ANNUAL PROGRESS REPORT \\ Dr. Michael A. Duncan \\ University of Georgia \\ Research Foundation \\ Athens, Georgia
}

May 1992

\section{PREPARED FOR THE \\ U. S. DEPARTMENT OF ENERGY \\ UNDER GRANT \\ DE-FG09-90ER14156}

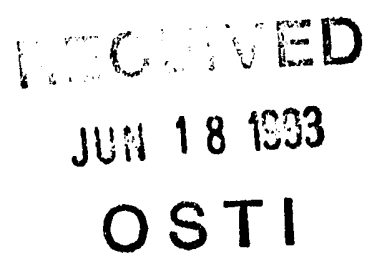

DISCLAIMER

This report was prepared as an account of work sponsored by an agency of the United States Government. Neither the United States Government nor any agency thereof, nor any of their employees, makes any warranty, express or implied, or assumes any legal liability or responsibility for the accuracy, completeness, or usefulness of any information, apparatus, product, or process disclosed, or represents that its use would not infringe privately owned rights. Reference herein to any specific commercial product, process, or service by trade name, trademark, manufacturer, or otherwise does not necessarily constitute or imply its endorsement, recommendation, or favoring by the United States Government or any agency thereof. The views and opinions of authors expressed herein do not necessarily state or reflect those of the United States Government or any agency thereof. 


\title{
Progress Report
}

\section{PHOTODISSOCIATION AND SPECTROSCOPY OF GAS PHASE BIMETALLIC CLUSTERS}

\author{
Michael A. Duncan \\ Department of Chemistry \\ University of Georgia \\ Athens, Georgia 30602
}

Research Scope and Objectives

The focus of our research program is the study of gas phase metal clusters to evaluate their potential to model fundamental interactions present on metal surfaces. To do this, we characterize the chemical bonding present between the component atoms in clusters as well as the bonding exhibited by adsorption on cluster surfaces. Electronic spectra, vibrational frequencies and bond dissociation energies are measured for both neutral and ionized clusters with a variety of laser/mass spectrometry techniques. We are particularly interested in bimetallic cluster systems composed of main group-transition metal mixtures.

Description of Research Effort

Our research program is composed of two main parts. In the first, metal-metal bonding interactions are probed through the study of bare metal clusters. Main grouptransition metal mixtures (e.g., $\mathrm{Bi} / \mathrm{Cr}, \mathrm{Bi} / \mathrm{Fe}, \mathrm{Ag} / \mathrm{Fe}, \mathrm{Al} / \mathrm{Cr}$ ) are produced in molecular beam environments with a pulsed nozzle laser vaporization source. Resonant two-photon ionization spectroscopy (R2PI) is employed to obtain electronic spectroscopy of neutral clusters, while mass-selected photodissociation spectroscopy provides similar information for cluster ions. In the ion experiments, the energies at which dissociation occurs and the resulting mass spectrum of dissociation products provides metal-metal bond dissociation energies. Both experiments yield cluster electronic states and, in favorable cases, vibrational and rotational energy levels.

The second focus of our research is on the weak bonding interactions exhibited by adsorption on metal cluster surfaces. Molecular beam techniques like those above are used to synthesize weakly bound complexes containing a metal cluster and a small molecule or rare gas atom. In neutral complexes, van der Waals, dipole-induced dipole, dipole-dipole, etc. interactions are studied, while ionized systems introduce the added dimension of chargeinduced dipole, etc. forces. 
In both areas, the goal is to characterize the fundamental interactions present in single component metal clusters and then to measure the modified or new features introduced with a corresponding bimetallic.

Progress to Date

Small bimetallic cluster cations containing the metals $\mathrm{Bi} / \mathrm{Cr}$ and $\mathrm{Bi} / \mathrm{Fe}$ have been synthesized and subjected to mass-selected phoiodissociation at various ultraviolet wavelengths in a reflectron time-of-flight mass spectrometer system. ${ }^{1}$ Photodissociation channels indicate that the heteronuclear bonding in these systems is comparable in strength to the respective homonuclear bonding interactions. Lower limits on the dissociation energies $\left(D_{0}{ }^{\prime \prime}\right)$ are obtained for the bimetallic dimers Bi-Fe $(\geq 1.85 \mathrm{eV}), \mathrm{Bi}^{+}-\mathrm{Fe}(\geq 1.85 \mathrm{eV})$, $\mathrm{Bi}-\mathrm{Cr}(\geq 2.58 \mathrm{eV})$ and $\mathrm{Bi}-\mathrm{Cr}^{+}(\geq 2.06 \mathrm{eV})$. These are the first data available for main grouptransition metal heteronuclear dimers. The bulk mixtures of these metals do not exist as stable solids, but the microscopic cluster particles can be synthesized and (as these studies show) they have significant covalent bonding.

Similar photodissociation studies have been performed on bimetallic cluster cations containing $\mathrm{Sn} / \mathrm{Bi}$ and $\mathrm{Pb} / \mathrm{Sb}$ mixtures. ${ }^{2}$ Product channels in these systems are compared to those in the corresponding pure component clusters. Highly non-statistical stoichiometries are observed in the product branching ratios of the bimetallic systems. The branching ratios can be rationalized, and also predicted (qualitatively) when a simple electron counting rule is employed to determine which bimetallic systems are closed shelled molecules. The electron counting rule assumes that the bonding in these systems involves inert $s$ orbitals, and occurs through both localized and delocalized $p$ bonding.

These photodissociation experiments utilize a new reflectron time-of-flight mass spectrometer system. The design of this instrument and its application for photodissociation experiments have been developed in our laboratory. To fully characterize its performance, we have conducted various calibration tests and ion trajectory calculations. The details of these experiments and guidelines for operating this kind of instrument have been presented in a recent publication. ${ }^{3}$

Silver dimer van der Waals complexes have been produced with a series of rare gas atoms $\left(\mathrm{Ag}_{2}-\mathrm{Ar}, \mathrm{Ag}_{2}-\mathrm{Kr}, \mathrm{Ag}_{2}-\mathrm{Xe}\right)$. R2PI electronic spectroscopy has been applied to these systems, yielding their vibrational frequencies and dissociation energies. ${ }^{4,5}$ Electronic spectra are observed to be red-shifted with respect to the $\mathrm{Ag}_{2} \mathrm{~B} \leftarrow \mathrm{X}$ electronic transition. As shown in Table 1, the complete set of three vibrational frequencies in the excited state are obtained for each of these complexes. Extended progressions in the metal-rare gas stretching vibrational mode make it possible to model the excited state potential surfaces and to obtain the dissociation energies. Combination with the spectral red shift and the known origin of the $\mathrm{Ag}_{2}$ electronic state provides the ground state dissociation energies for each complex. The dissociation energies obtained are within a factor of two of the desorption energies for these rare gases from the $\mathrm{Ag}(111)$ surface. 
Table 1. Spectroscopic constants for $\mathrm{Ag}_{2}-\mathrm{Ar}, \mathrm{Ag}_{2}-\mathrm{Kr}$ and $\mathrm{Ag}_{2}$-Xe complexes. All entries are in $\mathrm{cm}^{-1}$ units. $\omega_{1}$ is the $\mathrm{Ag}-\mathrm{Ag}$ stretch, $\omega_{2}$ is the RG bend and $\omega_{3}$ is the RG stretch.

\begin{tabular}{lcccc}
\hline & $\mathrm{Ag}_{2}-\mathrm{Ar}$ & $\mathrm{Ag}_{2}-\mathrm{Kr}$ & $\mathrm{Ag}_{2}-\mathrm{Xe}$ & $107,109 \mathrm{Ag}_{2}$ \\
\hline$\omega_{1}{ }^{\prime}$ & 156.3 & 157.7 & 165.3 & 151.3 \\
$\omega_{2}{ }^{\prime}$ & 28.3 & 27.9 & 25.7 & - \\
$\omega_{3}{ }^{\prime}$ & 73.9 & 72.6 & 79.9 & - \\
$\mathrm{D}_{0}{ }^{\prime}$ & 755 & 1205 & 2761 & - \\
$\mathrm{D}_{0}{ }^{\prime}$ & 275 & 394 & 1243 & -
\end{tabular}

We have been working on an improved molecular beam source for the generation of both bimetallic and pure component metal clusters. This new source uses a pulsed hollow cathode discharge in a pulsed supersonic expansion. While cther research groups have described electrical discharge cluster sources, our hollow cathode design provides improved metal sputtering yields, more stable shot-to-shot signals, and better cooling of the metal cluster species formed. The advantage of this kind of source in general is that it is far less expensive than a laser source while providing similar performance.

\section{Future Research}

Ongoing work and work planned for the upcoming year includes the photodissociation of silver clusters in mixtures with the transition metals chromium, iron and molybdenum. We also plan to study R2PI spectroscopy of silver dimer complexes with small molecules such as $\mathrm{CO}_{2}, \mathrm{~N}_{2}$ and $\mathrm{H}_{2} \mathrm{O}$. Bimetallic effects will be probed in similar studies of $\mathrm{AgCu}$ complexes. In heteronuclear dimers, the van der Waals forces we have already investigated will be modified because of the dipole moment. 
Publications Resulting From This Work

1. T.G. Taylor, K.F. Willey, M.B. Bishop and M.A. Duncan, "Photodissociation of MassSelected Bi/Cr and Bi/Fe Bimetallic Clusters," J. Phys. Chem. 1990, 94, 8016.

2. T.G. Taylor, K.F. Willey and M.A. Duncan, "Photodissociation of $\mathrm{Pb} / \mathrm{Sb}$ Bimetallic Clusters," in preparation.

3. D.S. Cornett, M. Peschke, K. LaiHing, P.Y. Cheng, K.F. Willey, and M.A. Duncan, "A Reflectron Time-of-Flight Mass Spectrometer for Laser Photodissociation," Rev. Sci. Instrum. 1992, 63, 2177.

4. K.F. Willey, P.Y. Cheng, C.S. Yeh, D.L. Robbins and M.A. Duncan, "Electronic Spectroscopy of Silver Dimer Rare Gas Complexes," J. Chem. Phys. 1991, 95, 6249.

5. D.L. Robbins, K.F. Willey, C.S. Yeh and M.A. Duncan, "Electronic Spectroscopy of $\mathrm{Ag}_{2}-\mathrm{Xe}, " J$. Phys. Chem., in press.

6. J.S. Pilgrim and M.A. Duncan, "Pulsed Hollow Cathode Electric Discharge Metal Cluster Source," in preparation.

Invited Lectures Presented on This Research

1. "Spectroscopy and Photochemistry of Mass-Selected Cluster Complexes," Physical Chemistry Seminar, University of Florida, April 4, 1991.

2. "Electronic Spectroscopy of Metal Dimer Rare Gas Complexes," Symposium on Metal-Rare Gas Interactions, National Meeting of the American Physical Society, Washington, DC, April 1991.

3. "Spectroscopy and Photochemistry in Clusters and Cluster Complexes", Physical Chemistry Seminar, University of Edinburgh, Scotland, September 1991.

4. "Spectroscopy at Metal Cluster Surfaces," Symposium on Cluster Spectroscopy, Southeast Regional Meeting of the American Chemical Society, Richmond, VA, November 1991. 
Other Lectures and Contributed Papers on This Research

1. M.A. Duncan, "Spectroscopy of Rare Gas Adsorption on Metal Cluster Surfaces," 1992 DOE Surface Chemistry and Catalysis Contractor's Meeting, Santa Monica, CA, March 1992.

2. D.L. Robbins, K.F. Willey, C.S. Yeh, J.S. Pilgrim, J.E. Salcido and M.A. Duncan, "Spectroscopy and Photochemistry of Metal Dimer Rare Gas Complexes," XXth Informal Conference on Photochemistry, Atlanta, GA, April 1992.

3. I.E. Pilgrim and M.A. Duncan, "A Pulsed Electrical Discharge Metal Cluster Source," XXth Informal Conference on Photochemistry, Atlanta, GA, April 1992. 

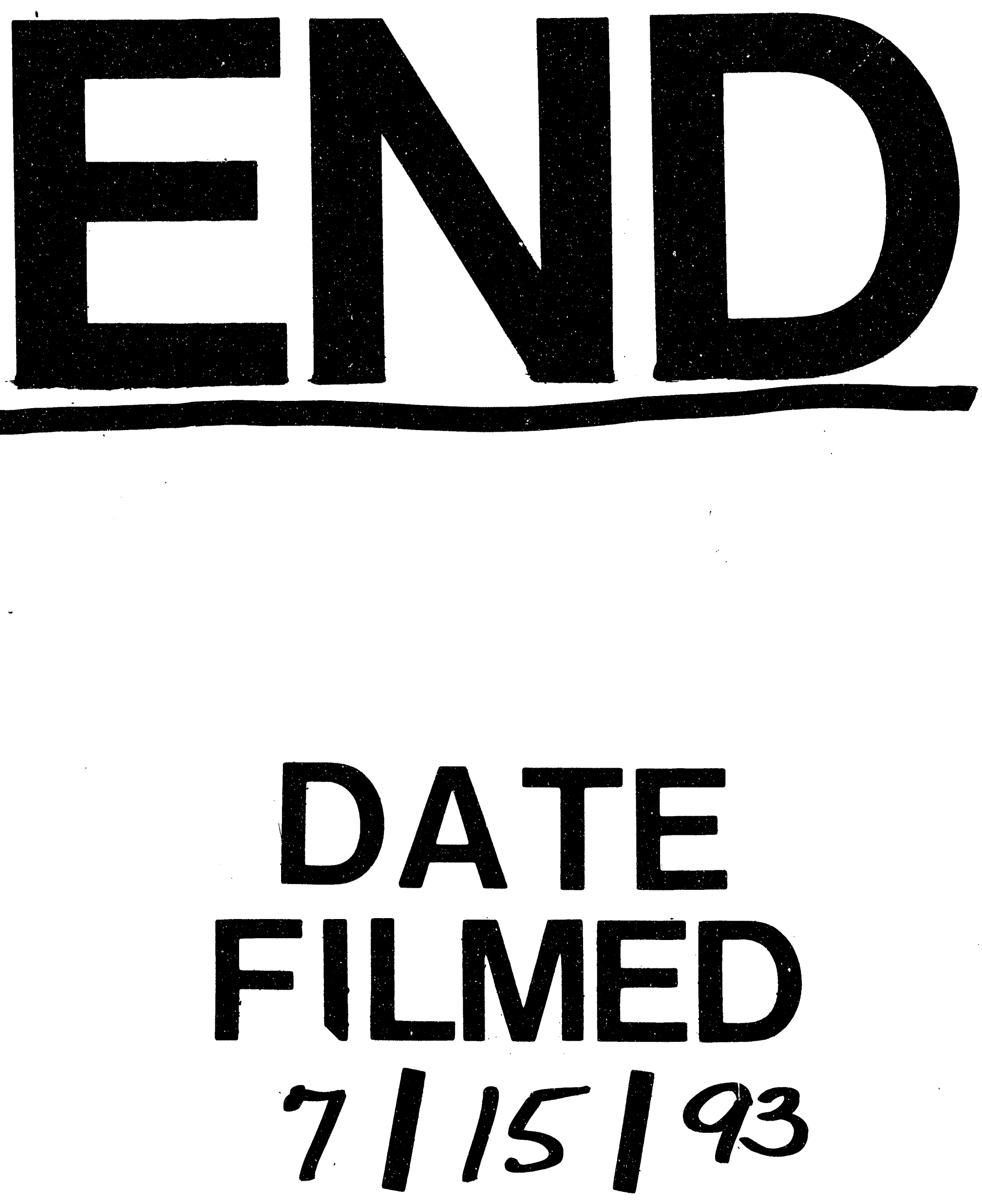

竞 
